\title{
Mitochondrial apoptosis: killing cancer using the enemy within
}

\author{
J Lopez ${ }^{1}$ and S W G Tait ${ }^{\star}{ }^{* 1}$ \\ ${ }^{1}$ Cancer Research UK Beatson Institute, Institute of Cancer Sciences, University of Glasgow, Garscube Estate, Switchback Road, \\ Glasgow, G61 1BD, UK
}

\begin{abstract}
Apoptotic cell death inhibits oncogenesis at multiple stages, ranging from transformation to metastasis. Consequently, in order for cancer to develop and progress, apoptosis must be inhibited. Cell death also plays major roles in cancer treatment, serving as the main effector function of many anti-cancer therapies. In this review, we discuss the role of apoptosis in the development and treatment of cancer. Specifically, we focus upon the mitochondrial pathway of apoptosis-the most commonly deregulated form of cell death in cancer. In this process, mitochondrial outer membrane permeabilisation or MOMP represents the defining event that irrevocably commits a cell to die. We provide an overview of how this pathway is regulated by BCL-2 family proteins and describe ways in which cancer cells can block it. Finally, we discuss exciting new approaches aimed at specifically inducing mitochondrial apoptosis in cancer cells, outlining their potential pitfalls, while highlighting their considerable therapeutic promise.
\end{abstract}

Every minute of life, millions of cells in our bodies undergo a regulated form of cell death called apoptosis. This altruistic cellular process plays varied and essential roles in keeping us healthy, not least in protecting us from cancer. Many oncogenic stresses, including uncontrolled proliferation or DNA damage, trigger apoptosis; consequently, by culling cells at risk of transformation, apoptosis effectively prevents cancer. Apoptosis also suppresses tumourigenesis in various other ways. For example, matrix detachment of cells-a pre-requisite for metastatic diseaseinduces a form of apoptosis called anoikis. In short, for cancer to initiate and progress, apoptosis must be inhibited at multiple stages. Cell death also plays key roles in the treatment of cancer. The best way to treat cancer is to kill it; indeed many anti-cancer therapies do this by inducing cell death through various mechanisms. Therefore, inhibition of cell death can act as a double-whammy that both promotes tumourigenesis and inhibits treatment responses. Nevertheless, although inhibition of cell death promotes cancer, tumour cells themselves often remain sensitive to apoptosis. Indeed, cancer cells are often more sensitive to cell death than normal tissue. As we will discuss in more detail later, this paradox can be explained because of the inherent stresses that tumour cells face, effectively pushing them closer to the edge. Importantly, this can provide a therapeutic window to selectively trigger tumour death. In this mini-review, we will discuss the role of cell death in cancer development and treatment, specifically focusing upon the mitochondrial pathway of apoptosis. Besides being the most commonly deregulated type of cell death in cancer, our understanding of mitochondrial apoptosis is now such that novel therapies have been developed to specifically engage mitochondrial apoptosis. Although we will restrict our discussion to mitochondrial apoptosis, it is important to note that other forms of programmed cell death, notably necroptosis also exist. Unlike apoptosis, necroptosis does not require mitochondria to execute, but it is currently unclear whether targeting necroptosis is possible or indeed beneficial in cancer (Tait et al, 2013). Here, in a progressive manner, we will outline the mitochondrial apoptotic pathway, describe how tumour cells block it and then discuss exciting new targeted therapies that exploit mitochondrial apoptosis in cancer treatment.

\section{MITOCHONDRIA AND CELL DEATH-FROM ENGINE} ROOM TO EXECUTIONER

Mitochondria are essential for life, mainly owing to their role in key biosynthetic processes such as ATP generation. Paradoxically, in the mid-1990s, evidence emerged implicating a central role for mitochondria in apoptotic cell death. Caspase protease activity is essential for apoptosis; once active, caspases cleave hundreds of

*Correspondence: Dr SWG Tait; E-mail: stephen.tait@glasgow.ac.uk

Received 10 November 2014; revised 26 January 2015; accepted 28 January 2015;

published online 5 March 2015

(c) 2015 Cancer Research UK. All rights reserved 0007-0920/15

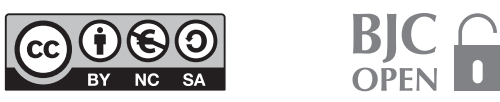


different proteins leading to rapid cell death with distinctive biochemical and morphological hallmarks (Taylor et al, 2008). In general terms, caspase activity can be initiated either via cellsurface death-receptors-the so-called death receptor or extrinsic pathway (reviewed in Dickens et al (2012)) or through the mitochondrial, also called intrinsic, pathway of apoptosis (Tait and Green, 2010). Most stimuli induce apoptosis via the mitochondrial pathway; in this process, the defining event is mitochondrial outer membrane permeabilisation or MOMP. Following MOMP, mitochondrial intermembrane space proteins, notably cytochrome $c$, are released into the cytosol whereupon they activate caspases. In mitochondrial ATP generation, cytochrome $c$ has an essential day-job, shuttling electrons between complexes III and IV of the electron transport chain. However, once released from mitochondria, cytochrome $c$ adopts a lethal function that is essential for caspase activation. Once in the cytosol, cytochrome $c$ binds the adaptor molecule APAF-1; this leads to extensive conformational changes in APAF-1, causing it to oligomerise and form a heptameric structure called the apoptosome. The apoptosome recruits and activates pro-caspase- 9 that in turn cleaves and activates the executioner caspases-3 and -7. Executioner caspase activity effectively kills the cell within minutes through the parallel cleavage of hundreds of different substrates. Besides cytochrome $c$, mitochondria release a variety of other proteins that promote caspase activity following MOMP-these include SMAC (also called Diablo) and Omi (also called HtrA2). By antagonising an endogenous inhibitor of caspase function called XIAP, Smac and Omi facilitate caspase activity. Importantly, MOMP often leads to cell death irrespective of caspase activity (Tait et al, 2014). This alternate, caspase-independent form of cell death most likely relates to the extensive nature of MOMP such that often all mitochondria undergo permeabilisation leading to a progressive and overwhelming loss of mitochondrial function (Lartigue et al, 2009).

Because MOMP effectively represents a point-of-no-return, it is highly regulated, largely by members of the BCL-2 protein family. This family can be sub-divided into pro-apoptotic effector proteins (BAX and BAK), pro-apoptotic BH3-only proteins (BID, BIM, PUMA, Noxa, HRK, BIK, BMF, BAD) and anti-apoptotic BCL-2 proteins (BCL-2, BCL-xL, MCL-1, A1, BCL-B, BCL-w) (Figure 1). Active $\mathrm{BAX}$ or $\mathrm{BAK}$ are required to permeabilise the mitochondrial outer membrane, although how they achieve this remains contentious. Most often, BAX or BAK activation requires direct interaction with a member of the $\mathrm{BH} 3$-only protein family. This causes BAX and BAK conformational changes, leading to their oligomerisation within the mitochondrial outer membrane. Somehow, BAX or BAK oligomers permeabilise the mitochondrial outer membrane, possibly indirectly by inducing lipid pores or, alternatively, by directly forming pores themselves. BH3-only proteins act as stress sentinels that relay the diverse array of apoptotic signals towards mitochondria and MOMP via BAX/BAK activation. Importantly, the $\mathrm{BH} 3$-only protein family can be subdivided into activators-able to directly activate BAX/BAK or sensitisers-that neutralise the apoptotic brake offered by antiapoptotic BCL-2 proteins. Most drugs that mimic BH3-only proteins (called $\mathrm{BH} 3$ mimetics) phenocopy sensitiser proteins. Counteracting BAX and BAK activity are the anti-apoptotic BCL-2 proteins. These prevent MOMP and apoptosis by binding $\mathrm{BH} 3-$ only proteins (preventing their interaction with BAX and BAK) or by binding activated BAX or BAK. Pro- and anti-apoptotic BCL-2 protein interactions are mediated between $\mathrm{BH} 3$ domains (present on BH3-only proteins and activated BAX or BAK) and the hydrophobic $\mathrm{BH} 3$-binding cleft in anti-apoptotic BCL-2 proteins. Competitive disruption of these interactions, leading to sensitisation or induction of apoptosis, forms the basis of $\mathrm{BH} 3$ mimetic biological activity. It is also important to note that BCL-2 proteins also have roles in non-apoptotic cellular processes, for example, calcium homeostasis (Bonneau et al, 2013).

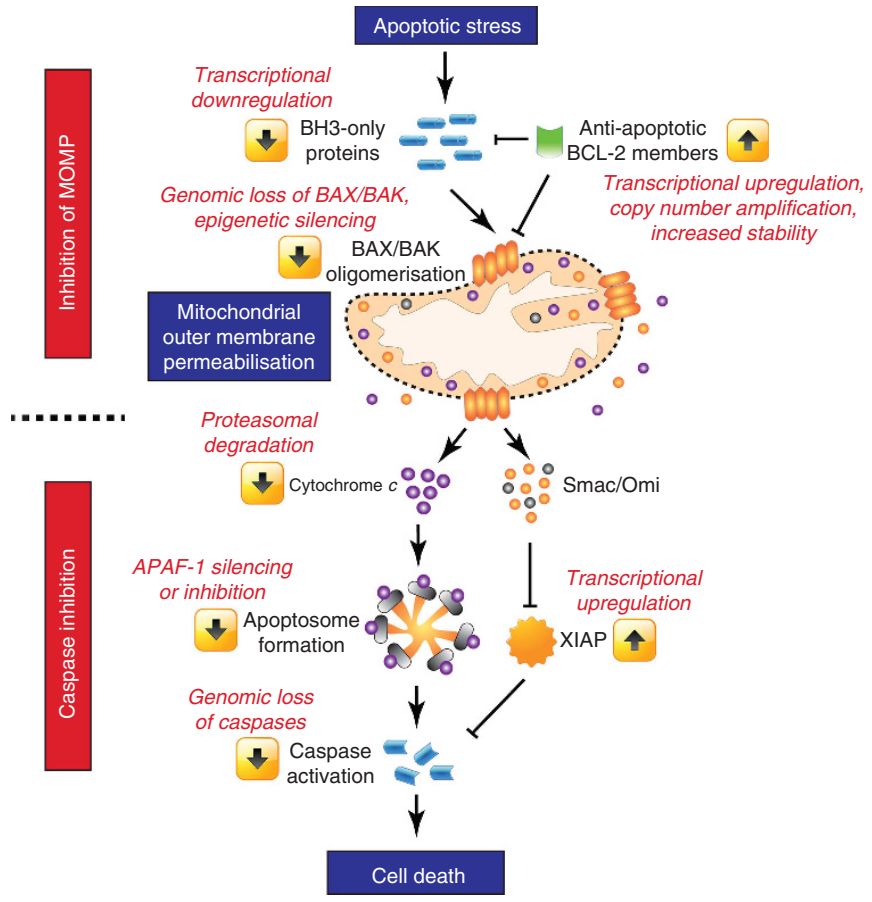

Figure 1. Execution of mitochondrial apoptosis and escape mechanisms. Apoptotic stresses promote accumulation of $\mathrm{BH}$-only proteins leading to BAX/BAK oligomerisation, MOMP and release of intermembrane space proteins. Cytochrome $c$ leads to apoptosome formation, which results in caspase activation and apoptosis. Smac and Omi neutralise the caspase inhibitor XIAP. Various strategies to escape apoptosis either by inhibiting MOMP or caspases are presented in red.

EVADING APOPTOSIS: HOW CANCER CELLS DODGE THE BULLET

Cancer cells use an abundant array of means to inhibit mitochondrial apoptosis. As we will discuss now, these can be divided into mechanisms that either prevent MOMP or inhibit caspase function downstream of MOMP (Figure 1).

Failing to pull the trigger-inhibiting mitochondrial permeabilisation. Cancer cells often block apoptosis by upregulating antiapoptotic BCL-2 proteins thereby preventing MOMP. Indeed, the gene encoding BCL-2 was first identified at a chromosomal translocation breakpoint that places BCL-2 under immunoglobulin heavy chain enhancer transcriptional control, leading to constitutively high BCL-2 expression (Tsujimoto et al, 1984). BCL-2 expression in itself is not oncogenic but dramatically enhances tumour onset in combination with growth-promoting oncogenes (Strasser et al, 1990). Extending these findings, many studies have shown that the upregulation of anti-apoptotic BCL-2 proteins is a feature common to diverse cancers. Mechanisms of upregulation are varied but include copy number amplification, transcriptional upregulation (driven by oncogenic signalling) or downregulation of microRNAs that suppress anti-apoptotic BCL-2 protein expression (Garzon et al, 2009; Beroukhim et al, 2010). Certain anti-apoptotic BCL-2 family members, notably MCL-1, are unstable and targeted for proteasome-dependent degradation; accordingly, mechanisms stabilising MCL-1 (thereby enhancing its anti-apoptotic activity) have also been described in cancer (Wertz et al, 2011).

Cancer cells have also developed a variety of means to disable the trigger that engages cell death. A classic example is the widespread loss of $\mathrm{p} 53$ tumour suppressor function seen across the tumour spectrum. p53 has multiple effector functions one of which 
is to induce apoptosis through the upregulation of $\mathrm{BH}$-only proteins, notably PUMA. Accordingly, the loss of p53 prevents DNA-damage-induced apoptosis in some cell types (Clarke et al, 1993; Lowe et al, 1993). Fortunately, DNA damage triggered by chemo- or radiotherapy can also elicit p53-independent apoptosis. Genomic loss of the key apoptotic effectors BAX or BAK has also been observed in a variety of cancer types. Although mouse knockout studies suggest that these two proteins have largely redundant functions, recent work argues that the loss of either protein in the context of activating $\mathrm{BH} 3$-only protein or antiapoptotic BCL-2 repertoire results in a strict apoptotic dependence for either BAX or BAK (Wang and Youle, 2012; Sarosiek et al, 2013). Besides inhibiting BAX or BAK function, the loss of various pro-apoptotic $\mathrm{BH} 3$-only proteins including NOXA, PUMA and BIM has also been documented in various tumours either by deletion or through promoter methylation leading to transcriptional silencing.

Putting the bullet back in the gun-blocking caspase function. Cancer cells also inhibit caspase function following MOMP (Figure 1). From our earlier discussion, this may appear futile given that MOMP is generally considered a point of no return. However, cells can survive MOMP in some circumstances; although best described in post-mitotic cells such as neurons, the ability of tumour cells to undergo MOMP and proliferate has also been reported (Martinou et al, 1999; Deshmukh et al, 2000; Putcha et al, 2000; Colell et al, 2007). Survival under these conditions requires caspase inhibition and a source of intact mitochondria-in line with this requirement, MOMP is not always complete such that some mitochondria can remain intact (Tait et al, 2010). Cells inhibit caspase function through various means. These include downregulating apoptosome activity by epigenetic silencing or inhibitory phosphorylation of APAF-1. Additionally, cytochrome $c$ itself can be targeted for ubiquitination and proteasome-dependent degradation following MOMP, thereby nullifying its pro-apoptotic activities (Gama et al, 2014). Caspase function can be directly inhibited by XIAP or indirectly by c-IAP1 or c-IAP2 through their ability to bind and neutralise the XIAP inhibitors SMAC and Omi. Clearly, various means exist that allow cells to effectively nullify caspase activity. Nevertheless, defining the occurrence of cancer cell recovery from MOMP in vivo and understanding its impact on tumourigenesis and treatment outcome requires further investigation.

HARNESSING THE HITMAN: USING APOPTOSIS TO KILL CANCER

The realisation that apoptosis is a programmed process that requires specific proteins paved the way to directly target cell death in cancer. Many conventional anti-cancer therapies induce apoptosis, albeit in indirect ways. However, our extensive molecular understanding of apoptosis gained over the last 20 years has led to the development of various drugs that directly kill cancer cells through apoptosis. These include death-receptor ligands, notably TRAIL, that trigger the extrinsic apoptotic pathway and SMAC-mimetics, that were designed to enhance caspase activation (Fulda and Vucic, 2012; Lemke et al, 2014). We will focus our discussion on extensive efforts aimed to trigger mitochondrial apoptosis in cancer cells by targeting the BCL-2 protein family.

Cancer cells and their suicidal tendencies. How can tumours be selectively killed via mitochondrial apoptosis? As alluded to earlier, based on the necessity to evade apoptosis during oncogenesis, a common misconception is that tumours are inherently apoptosis resistant. Often this is not the case, indeed the opposite can hold true, cancer cells are frequently more sensitive than normal tissue to therapy-induced apoptosis. The reasons for this are varied, but include oncogenic stress (that are often inherently apoptotic) and environmental stresses such as hypoxia or low-nutrient availability that cancers often face. Irrespective of source, such stresses increase the sensitivity of cancer cells (relative to normal, healthy cells) to undergo MOMP and die-cells in this state have been termed as being 'primed for death' (Certo et al, 2006) (Figure 2). The basis of priming revolves around levels of pro-apoptotic BH3-only and anti-apoptotic BCL-2 proteins. Importantly, the extent of priming can be revealed by a technique called $\mathrm{BH} 3$ profiling (Certo et al, 2006). Using $\mathrm{BH} 3$ peptides derived from different $\mathrm{BH} 3$-only proteins, this technique not only estimates the extent of cell priming in a tumour but also gives an indication of the BCL-2 family proteins on which it requires to survive. Primed cells have higher pro-apoptotic $\mathrm{BH} 3$-only protein loads that, through necessity, require higher anti-apoptotic BCL-2 levels to ensure survival (Figure 2). In this way, primed cells are addicted to antiapoptotic BCL-2 function. In practical terms, this means that primed cancer cells are closer to the edge such that an additional pro-apoptotic stress-for example, chemo- or radiotherapy-can kill these cells more readily than non-primed tissue. Additionally, the extent of priming in healthy tissue also dictates dose-limiting toxicities of anti-cancer therapies. Underscoring the clinical importance of priming, different studies have shown that the extent of tumour cell apoptotic priming correlates with therapeutic responses and clinical prognosis (Ni Chonghaile et al, 2011; Vo et al, 2012). In addition to dictating the sensitivity of normal and tumour cells to conventional anti-cancer therapies, priming also dictates the efficacy of new therapies that directly target MOMP through the BCL-2 protein family.

Exploiting an addiction: drugging the BCL-2 family. Most strategies to directly engage MOMP in cancer treatment have centred upon blocking anti-apoptotic BCL-2 function-the rationale being that this should either directly trigger apoptosis or sensitise to an additional pro-apoptotic therapy (e.g., radiotherapy). Developing drugs that target anti-apoptotic BCL-2 function is challenging, not least because it entails developing an inhibitor of protein-protein interactions that targets a shallowhydrophobic groove. Nevertheless, effective and specific inhibitors of BCL-2 proteins have been developed, initially using a highthroughput NMR-based screen to identify chemical fragments that bound the hydrophobic BH3-binding groove of BCL-xL (Oltersdorf et al, 2005). Chemical coupling of binding fragments to generate high-affinity ligands led to the development of ABT737, the prototypic $\mathrm{BH} 3$ mimetic that displays sub-nanomolar affinity for BCL-xL (Oltersdorf et al, 2005). ABT-737 and ABT-263 (its more-soluble clinically applicable analogue) both display binding profiles similar to the $\mathrm{BH}$-only protein $\mathrm{BAD}$, such that they bind BCL-xL, BCL-2 but not MCL- 1 . In a variety of cell and animal models, ABT-737 and ABT-263 exhibit potent antitumour activity either as single agents or in combination therapy (Oltersdorf et al, 2005; Tse et al, 2008). Unfortunately, the clinical application of ABT-263 is limited because it induces thrombocytopenia (Tse et al, 2008; Josefsson et al, 2011). This on-target effect is due to BCL-xL neutralisation on aged platelets leading to their apoptotic death. To circumvent this problem, a $\mathrm{BH} 3$ mimetic specifically targeting BCL-2 has been developed-this compound, ABT-199, was generated through structure-guided chemical modification of ABT-263 (Souers et al, 2013). Attesting to its on-target potency, initial administration of ABT-199 in chronic lymphocyte leukaemia (CLL) was shown to cause tumour lysis syndrome through massive induction of apoptosis (Ng and Davids, 2014). Step-wise dose escalation should ameliorate this problem and initial clinical trials of ABT-199 use in the treatment of CLL look promising with many patients displaying responses. 

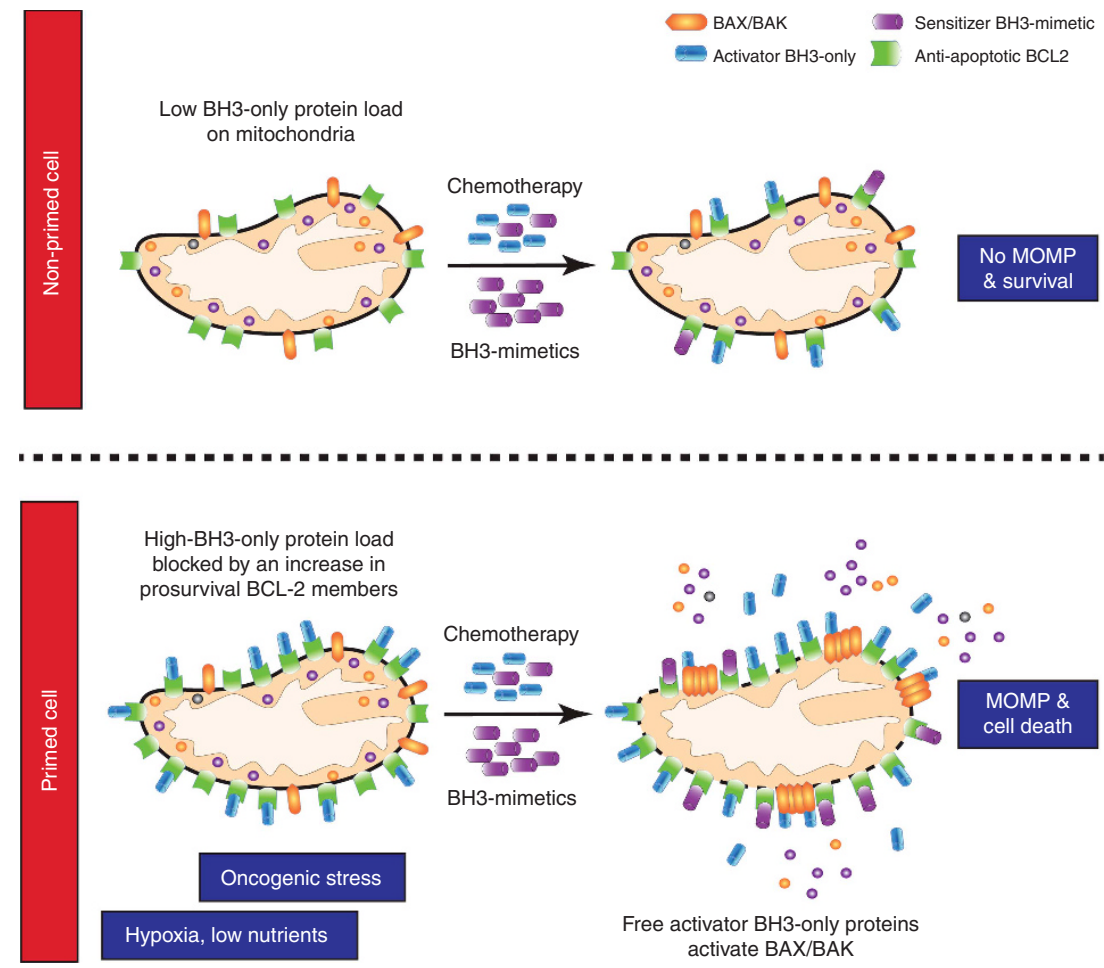

Figure 2. Mitochondrial priming model. In non-primed cells (top panel), mitochondria have a low BH3-only protein load leaving excess prosurvival $\mathrm{BCL} 2$ proteins to neutralise pro-apoptotic $\mathrm{BH}$-only proteins resulting from cytotoxic chemotherapy or $\mathrm{BH}$-mimetic treatment. In primed cancer cells (bottom panel), stresses such as oncogene activation lead to a high BH3-only protein load blocked by a compensatory increase in pro-survival $\mathrm{BCL} 2$ members. Additional pro-apoptotic stimuli result in excess activator BH3-only proteins that cause BAX/BAK activation, MOMP and death in these cells.

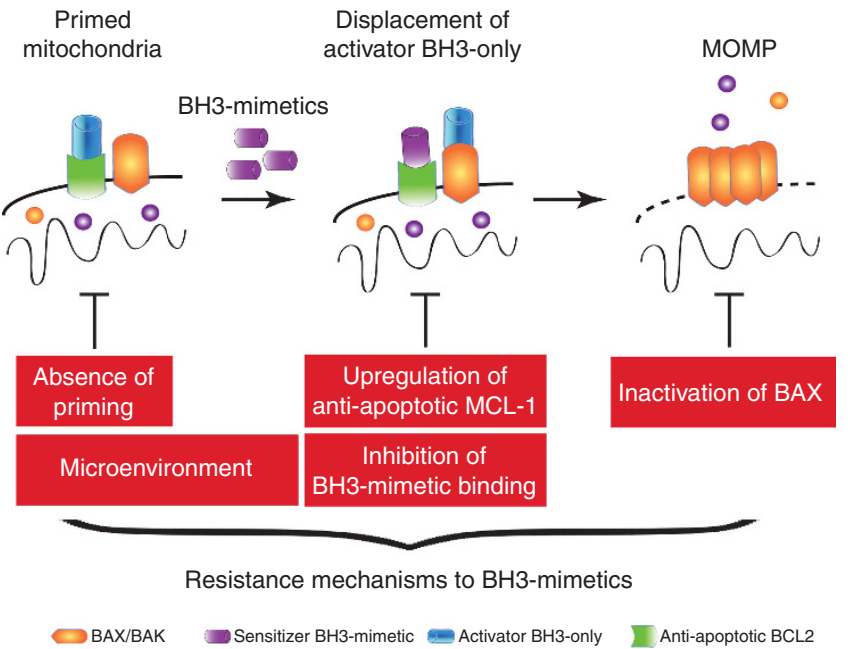

Figure 3. BH3-mimetic resistance mechanisms. In primed mitochondria, sensitiser $\mathrm{BH} 3$ mimetics promote MOMP by displacing activator $\mathrm{BH}$-only proteins. Resistance strategies discussed in the review are highlighted in red.

Cancer cells' lust for life: $\mathrm{BH} 3$ mimetic resistance mechanisms. As with all targeted therapies, resistance-either pre-existing or acquired-presents a considerable challenge to the use of $\mathrm{BH} 3$ mimetics in cancer therapy (Figure 3). Considering the rapid effects of $\mathrm{BH} 3$ mimetics on MOMP induction coupled with it often being a point-of-no-return, acquired resistance to $\mathrm{BH} 3$ mimetics is perhaps difficult to envision. Nevertheless, a recent report demonstrated acquired resistance to the BCL-2-specific mimetic ABT-199 in two different experimental lymphoma models; one was due to an inactivating mutation in BAX, whereas the other was a BCL-2 mutation that curiously ablated its inhibition by ABT-199 whilst maintaining anti-apoptotic activity (Fresquet et al, 2014). Currently utilised $\mathrm{BH} 3$ mimetics face various, formidable intrinsic mechanisms of resistance. One of the biggest is the current lack of effective inhibitors targeting all anti-apoptotic BCL-2 proteins, notably MCL-1. Although not an issue in some cancers, including CLL and acute myeloid leukaemia that display a strict dependence on BCL-2 for survival, it is likely to be critical in other cancers, particularly heterogenous solid tumours. Indeed, various studies have shown that MCL-1 expression allows cells to resist ABT-737 or ABT-263 treatment (van Delft et al, 2006). Nevertheless, effective inhibitors of MCL-1 and possibly other, currently nontargetable BCL-2 family members are likely to be developed soon, providing the opportunity to neutralise the whole anti-apoptotic BCL-2 family. At first take, this may seem desirable, maximising the sensitisation of cancer cells to death. However, broad neutralisation may elicit intolerable toxicity; besides the thrombocytopenia caused by BCL-xL inhibition, loss of MCL-1 function shows a variety of toxic effects in mice-though it is important to note that effects of transient pharmacological inhibition does not equate to irreversible loss of MCL-1 function induced in these mice (Thomas et al, 2013; Wang et al, 2013). Additionally, various studies argue that existing $\mathrm{BH} 3$ mimetics display differential potency for targeting one BCL-2 protein $v s$ another and between targeting specific BH3-only/BCL-2 complexes (Aranovich et al, 2012; Merino et al, 2012; Rooswinkel et al, 2012). In the latter example, ABT-737 effectively inhibits the $\mathrm{BH} 3$-only proteins $\mathrm{BAD}$ and BID from binding BCL-2 but is ineffective at preventing Bim from binding. Whether this holds true for clinically applicable $\mathrm{BH} 3$ mimetics is not known, but if so, it implies that these drugs may be less effective in tumours that require BCL-2 to neutralise BIM. Although often overlooked in experimental systems, the tumour 
microenvironment can massively affect cellular sensitivity to $\mathrm{BH} 3$ mimetics. For example, CLL cells resident in the lymph nodes are much more resistant to apoptosis than circulating ones. Mimicking the lymph node stromal and cytokine environment in vitro leads to a massive upregulation of different anti-apoptotic Bcl-2 proteins, including A1 (also called BFL-1) that is not inhibited by existing BH3 mimetics. Consequently, this renders CLL cells effectively resistant to ABT-737 (Vogler et al, 2009). The microenvironment can also affect BH3-mimetic sensitivity in other ways. For example, levels of pro-apoptotic NOXA are reduced, whereas anti-apoptotic MCL-1 levels are increased in lymph node vs peripheral CLL, thereby promoting $\mathrm{BH} 3-$ mimetic resistance in lymph noderesident CLL (Smit et al, 2007). Importantly, survival signalling by the TNF receptor family member CD40 that causes this deregulated NOXA/MCL-1 balance can be targeted thereby restoring cell death sensitivity (Hallaert et al, 2008). Another major means of cancer cell resistance to $\mathrm{BH} 3$-mimetic therapy is that cells simply are not primed. As discussed earlier, current $\mathrm{BH} 3$ mimetics mimic sensitiser $\mathrm{BH} 3$-only proteins in that they inhibit anti-apoptotic BCL-2 function. This in itself is insufficient to trigger apoptosis and an additional stimulus to activate BAX or BAK and MOMP is required. An obvious way to provide this is through a second apoptosis-engaging chemotherapy or radiotherapy. Alternatively, $\mathrm{BH} 3$ mimetics that mimic direct activator $\mathrm{BH} 3$-only proteins and trigger apoptosis could be developed. Along these lines, potent small molecular activators of BAX have been developed (Gavathiotis et al, 2012). With both approaches (combination therapy or BAX/BAK activators), a significant concern is that these will cause unacceptable toxicity in healthy tissue. However, one would still predict that increased priming of cancer cells would make them more sensitive, potentially offering a therapeutic window.

\section{SUMMARY}

As discussed, fantastic advances have been made over the last 20 years in our understanding of the mitochondrial apoptotic pathway and its role in cancer. The development and clinical application of $\mathrm{BH} 3$-mimetic drugs that specifically target mitochondrial apoptosis in cancer is a watershed moment. Nevertheless, many challenges remain, not least extending the utility of targeting mitochondrial apoptosis to diverse tumour types as well as circumventing mechanisms of resistance. Moreover, similar to conventional cancer therapies, it is clear that BH3-mimetic therapy also entails walking a therapeutic tightrope-balancing maximal tumour cell death $v s$ tolerable toxicities. These points notwithstanding, we anticipate that clinical application of existing and the development of novel approaches to directly target the mitochondrial apoptotic pathway will prove highly effective in cancer treatment.

\section{ACKNOWLEDGEMENTS}

The Tait lab is supported by funding from the Royal Society, EU and BBSRC. S.T. is a Royal Society University Research Fellow. J.L. is supported by a fellowship from fondation ARC. Owing to space constraints, we apologise for failing to cite many primary papers.

\section{REFERENCES}

Aranovich A, Liu Q, Collins T, Geng F, Dixit S, Leber B, Andrews DW (2012) Differences in the mechanisms of proapoptotic $\mathrm{BH} 3$ proteins binding to Bcl-XL and Bcl-2 quantified in live MCF-7 cells. Mol Cell 45(6): 754-763. Beroukhim R, Mermel CH, Porter D, Wei G, Raychaudhuri S, Donovan J, Barretina J, Boehm JS, Dobson J, Urashima M, Mc Henry KT,
Pinchback RM, Ligon AH, Cho YJ, Haery L, Greulich H, Reich M, Winckler W, Lawrence MS, Weir BA, Tanaka KE, Chiang DY, Bass AJ, Loo A, Hoffman C, Prensner J, Liefeld T, Gao Q, Yecies D, Signoretti S, Maher E, Kaye FJ, Sasaki H, Tepper JE, Fletcher JA, Tabernero J, Baselga J, Tsao MS, Demichelis F, Rubin MA, Janne PA, Daly MJ, Nucera C, Levine RL, Ebert BL, Gabriel S, Rustgi AK, Antonescu CR, Ladanyi M, Letai A, Garraway LA, Loda M, Beer DG, True LD, Okamoto A, Pomeroy SL, Singer S, Golub TR, Lander ES, Getz G, Sellers WR, Meyerson M (2010) The landscape of somatic copy-number alteration across human cancers. Nature 463(7283): 899-905.

Bonneau B, Prudent J, Popgeorgiev N, Gillet G (2013) Non-apoptotic roles of Bcl-2 family: the calcium connection. Biochim Biophys Acta 1833(7): 1755-1765.

Certo M, Del Gaizo Moore V, Nishino M, Wei G, Korsmeyer S, Armstrong SA, Letai A (2006) Mitochondria primed by death signals determine cellular addiction to antiapoptotic BCL-2 family members. Cancer Cell 9(5): 351-365.

Clarke AR, Purdie CA, Harrison DJ, Morris RG, Bird CC, Hooper ML, Wyllie AH (1993) Thymocyte apoptosis induced by p53-dependent and independent pathways. Nature 362(6423): 849-852.

Colell A, Ricci JE, Tait S, Milasta S, Maurer U, Bouchier-Hayes L, Fitzgerald P, Guio-Carrion A, Waterhouse NJ, Li CW, Mari B, Barbry P, Newmeyer DD, Beere HM, Green DR (2007) GAPDH and autophagy preserve survival after apoptotic cytochrome $\mathrm{c}$ release in the absence of caspase activation. Cell 129(5): 983-997.

Deshmukh M, Kuida K, Johnson Jr. EM (2000) Caspase inhibition extends the commitment to neuronal death beyond cytochrome $\mathrm{c}$ release to the point of mitochondrial depolarization. J Cell Biol 150(1): 131-143.

Dickens LS, Powley IR, Hughes MA, MacFarlane M (2012) The 'complexities' of life and death: death receptor signalling platforms. Exp Cell Res 318(11): 1269-1277.

Fresquet V, Rieger M, Carolis C, Garcia-Barchino MJ, Martinez-Climent JA (2014) Acquired mutations in BCL2 family proteins conferring resistance to the BH3 mimetic ABT-199 in lymphoma. Blood 123(26): 4111-4119.

Fulda S, Vucic D (2012) Targeting IAP proteins for therapeutic intervention in cancer. Nat Rev Drug Discov 11(2): 109-124.

Gama V, Swahari V, Schafer J, Kole AJ, Evans A, Huang Y, Cliffe A, Golitz B, Sciaky N, Pei XH, Xiong Y, Deshmukh M (2014) The E3 ligase PARC mediates the degradation of cytosolic cytochrome $\mathrm{c}$ to promote survival in neurons and cancer cells. Sci Signal 7(334): ra67.

Garzon R, Heaphy CE, Havelange V, Fabbri M, Volinia S, Tsao T, Zanesi N, Kornblau SM, Marcucci G, Calin GA, Andreeff M, Croce CM (2009) MicroRNA 29b functions in acute myeloid leukemia. Blood 114(26): 5331-5341.

Gavathiotis E, Reyna DE, Bellairs JA, Leshchiner ES, Walensky LD (2012) Direct and selective small-molecule activation of proapoptotic BAX. Nat Chem Biol 8(7): 639-645.

Hallaert DY, Jaspers A, van Noesel CJ, van Oers MH, Kater AP, Eldering E (2008) c-Abl kinase inhibitors overcome CD40-mediated drug resistance in CLL: implications for therapeutic targeting of chemoresistant niches. Blood 112(13): 5141-5149.

Josefsson EC, James C, Henley KJ, Debrincat MA, Rogers KL, Dowling MR, White MJ, Kruse EA, Lane RM, Ellis S, Nurden P, Mason KD, O'Reilly LA, Roberts AW, Metcalf D, Huang DC, Kile BT (2011) Megakaryocytes possess a functional intrinsic apoptosis pathway that must be restrained to survive and produce platelets. J Exp Med 208(10): 2017-2031.

Lartigue L, Kushnareva Y, Seong Y, Lin H, Faustin B, Newmeyer DD (2009) Caspase-independent mitochondrial cell death results from loss of respiration, not cytotoxic protein release. Mol Biol Cell 20(23): 4871-4884.

Lemke J, von Karstedt S, Zinngrebe J, Walczak H (2014) Getting TRAIL back on track for cancer therapy. Cell Death Differ 21(9): 1350-1364.

Lowe SW, Schmitt EM, Smith SW, Osborne BA, Jacks T (1993) p53 is required for radiation-induced apoptosis in mouse thymocytes. Nature 362(6423): 847-849.

Martinou I, Desagher S, Eskes R, Antonsson B, Andre E, Fakan S, Martinou JC (1999) The release of cytochrome c from mitochondria during apoptosis of NGF-deprived sympathetic neurons is a reversible event. J Cell Biol 144(5): 883-889.

Merino D, Khaw SL, Glaser SP, Anderson DJ, Belmont LD, Wong C, Yue P, Robati M, Phipson B, Fairlie WD, Lee EF, Campbell KJ, Vandenberg CJ, Cory S, Roberts AW, Ludlam MJ, Huang DC, Bouillet P (2012) Bcl-2, $\mathrm{Bcl}-\mathrm{x}(\mathrm{L})$, and $\mathrm{Bcl}-\mathrm{w}$ are not equivalent targets of ABT-737 and navitoclax (ABT-263) in lymphoid and leukemic cells. Blood 119(24): 5807-5816. 
Ng SY, Davids MS (2014) Selective Bcl-2 inhibition to treat chronic lymphocytic leukemia and non-Hodgkin lymphoma. Clin Adv Hematol Oncol 12(4): 224-229.

Ni Chonghaile T, Sarosiek KA, Vo TT, Ryan JA, Tammareddi A, Moore Vdel G, Deng J, Anderson KC, Richardson P, Tai YT, Mitsiades CS, Matulonis UA, Drapkin R, Stone R, Deangelo DJ, McConkey DJ, Sallan SE, Silverman L, Hirsch MS, Carrasco DR, Letai A (2011) Pretreatment mitochondrial priming correlates with clinical response to cytotoxic chemotherapy. Science 334(6059): 1129-1133.

Oltersdorf T, Elmore SW, Shoemaker AR, Armstrong RC, Augeri DJ, Belli BA, Bruncko M, Deckwerth TL, Dinges J, Hajduk PJ, Joseph MK, Kitada S, Korsmeyer SJ, Kunzer AR, Letai A, Li C, Mitten MJ, Nettesheim DG, Ng S, Nimmer PM, O'Connor JM, Oleksijew A, Petros AM, Reed JC, Shen W, Tahir SK, Thompson CB, Tomaselli KJ, Wang B, Wendt MD, Zhang H, Fesik SW, Rosenberg SH (2005) An inhibitor of Bcl-2 family proteins induces regression of solid tumours. Nature 435(7042): 677-681.

Putcha GV, Deshmukh M, Johnson Jr. EM (2000) Inhibition of apoptotic signaling cascades causes loss of trophic factor dependence during neuronal maturation. J Cell Biol 149(5): 1011-1018.

Rooswinkel RW, van de Kooij B, Verheij M, Borst J (2012) Bcl-2 is a better ABT-737 target than Bcl-xL or Bcl-w and only Noxa overcomes resistance mediated by Mcl-1, Bfl-1, or Bcl-B. Cell Death Dis 3: e366.

Sarosiek KA, Chi X, Bachman JA, Sims JJ, Montero J, Patel L, Flanagan A, Andrews DW, Sorger P, Letai A (2013) BID preferentially activates BAK while BIM preferentially activates BAX, affecting chemotherapy response. Mol Cell 51(6): 751-765.

Smit LA, Hallaert DY, Spijker R, de Goeij B, Jaspers A, Kater AP, van Oers MH, van Noesel CJ, Eldering E (2007) Differential Noxa/Mcl-1 balance in peripheral versus lymph node chronic lymphocytic leukemia cells correlates with survival capacity. Blood 109(4): 1660-1668.

Souers AJ, Leverson JD, Boghaert ER, Ackler SL, Catron ND, Chen J, Dayton BD, Ding H, Enschede SH, Fairbrother WJ, Huang DC, Hymowitz SG, Jin S, Khaw SL, Kovar PJ, Lam LT, Lee J, Maecker HL, Marsh KC, Mason KD, Mitten MJ, Nimmer PM, Oleksijew A, Park CH, Park CM, Phillips DC, Roberts AW, Sampath D, Seymour JF, Smith ML, Sullivan GM, Tahir SK, Tse C, Wendt MD, Xiao Y, Xue JC, Zhang H, Humerickhouse RA, Rosenberg SH, Elmore SW (2013) ABT-199, a potent and selective BCL-2 inhibitor, achieves antitumor activity while sparing platelets. Nat Med 19(2): 202-208.

Strasser A, Harris AW, Bath ML, Cory S (1990) Novel primitive lymphoid tumours induced in transgenic mice by cooperation between myc and bcl-2. Nature 348(6299): 331-333.

Tait SW, Green DR (2010) Mitochondria and cell death: outer membrane permeabilization and beyond. Nat Rev Mol Cell Biol 11(9): 621-632.

Tait SW, Ichim G, Green DR (2014) Die another way-non-apoptotic mechanisms of cell death. J Cell Sci 127(Pt 10): 2135-2144.

Tait SW, Oberst A, Quarato G, Milasta S, Haller M, Wang R, Karvela M, Ichim G, Yatim N, Albert ML, Kidd G, Wakefield R, Frase S, Krautwald S, Linkermann A, Green DR (2013) Widespread mitochondrial depletion via mitophagy does not compromise necroptosis. Cell Rep 5(4): 878-885.
Tait SW, Parsons MJ, Llambi F, Bouchier-Hayes L, Connell S, Munoz-Pinedo C, Green DR (2010) Resistance to caspase-independent cell death requires persistence of intact mitochondria. Dev Cell 18(5): 802-813.

Taylor RC, Cullen SP, Martin SJ (2008) Apoptosis: controlled demolition at the cellular level. Nat Rev Mol Cell Biol 9(3): 231-241.

Thomas RL, Roberts DJ, Kubli DA, Lee Y, Quinsay MN, Owens JB, Fischer KM, Sussman MA, Miyamoto S, Gustafsson AB (2013) Loss of MCL-1 leads to impaired autophagy and rapid development of heart failure. Genes Dev 27(12): 1365-1377.

Tse C, Shoemaker AR, Adickes J, Anderson MG, Chen J, Jin S, Johnson EF, Marsh KC, Mitten MJ, Nimmer P, Roberts L, Tahir SK, Xiao Y, Yang X, Zhang H, Fesik S, Rosenberg SH, Elmore SW (2008) ABT-263: a potent and orally bioavailable Bcl-2 family inhibitor. Cancer Res 68(9): 3421-3428.

Tsujimoto Y, Finger LR, Yunis J, Nowell PC, Croce CM (1984) Cloning of the chromosome breakpoint of neoplastic B cells with the $t(14 ; 18)$ chromosome translocation. Science 226(4678): 1097-1099.

van Delft MF, Wei AH, Mason KD, Vandenberg CJ, Chen L, Czabotar PE, Willis SN, Scott CL, Day CL, Cory S, Adams JM, Roberts AW, Huang DC (2006) The BH3 mimetic ABT-737 targets selective Bcl-2 proteins and efficiently induces apoptosis via Bak/Bax if Mcl-1 is neutralized. Cancer Cell 10(5): 389-399.

Vo TT, Ryan J, Carrasco R, Neuberg D, Rossi DJ, Stone RM, Deangelo DJ, Frattini MG, Letai A (2012) Relative mitochondrial priming of myeloblasts and normal HSCs determines chemotherapeutic success in AML. Cell 151(2): 344-355.

Vogler M, Butterworth M, Majid A, Walewska RJ, Sun XM, Dyer MJ, Cohen GM (2009) Concurrent up-regulation of BCL-XL and BCL2A1 induces approximately 1000 -fold resistance to ABT-737 in chronic lymphocytic leukemia. Blood 113(18): 4403-4413.

Wang C, Youle RJ (2012) Predominant requirement of Bax for apoptosis in HCT116 cells is determined by Mcl-1's inhibitory effect on Bak. Oncogene 31(26): 3177-3189.

Wang X, Bathina M, Lynch J, Koss B, Calabrese C, Frase S, Schuetz JD, Rehg JE, Opferman JT (2013) Deletion of MCL-1 causes lethal cardiac failure and mitochondrial dysfunction. Genes Dev 27(12): 1351-1364.

Wertz IE, Kusam S, Lam C, Okamoto T, Sandoval W, Anderson DJ, Helgason E, Ernst JA, Eby M, Liu J, Belmont LD, Kaminker JS, O’Rourke KM, Pujara K, Kohli PB, Johnson AR, Chiu ML, Lill JR, Jackson PK, Fairbrother WJ, Seshagiri S, Ludlam MJ, Leong KG, Dueber EC, Maecker H, Huang DC, Dixit VM (2011) Sensitivity to antitubulin chemotherapeutics is regulated by MCL1 and FBW7. Nature 471(7336): 110-114.

(c) (i) (2) This work is licensed under the Creative Commons (c) Attribution-Non-Commercial-Share Alike 4.0 International License. To view a copy of this license, visit http:// creativecommons.org/licenses/by-nc-sa/4.0/ 